\title{
Fracture Toughness of Microfiber Reinforced Cement Composites
}

\author{
Patricia Kim Nelson'; Victor C. Li, F.ASCE²; and Toshiro Kamada ${ }^{3}$
}

\begin{abstract}
An investigation into the reinforcing behavior of microdiameter fibers in cement composites, with an emphasis on their behavior in the frontal process zone (FPZ) ahead of the crack tip, is presented. Fracture toughness tests were conducted on thin sheet cement composites reinforced with polypropylene (PP), polyvinyl alcohol (PVA), and refined cellulose (RC) fibers under air-dry conditions. Fracture toughness in the absence of microscopic damage was quantified for these composites, as was fracture toughness that included the energy absorbed in the microcracked region prior to failure crack localization. These tests revealed that the PVA and RC fibers were able to effectively postpone microcrack formation, thereby delaying the localization of the failure crack. The PP fibers were not able to provide the same level of reinforcement. An optical microscope was used to monitor the progression of damage during testing. In addition, the acoustic emission technique was used to confirm the accuracy of the fracture toughness values.
\end{abstract}

DOI: 10.1061/(ASCE)0899-1561(2002)14:5(384)

CE Database keywords: Toughness; Fracture strength; Fiber reinforced materials; Cements; Damage; Composite materials.

\section{Introduction}

Fibers influence the fracture processes in composites ahead of the crack tip in the frontal process zone (FPZ) and behind the crack tip in the crack bridging wake (Fig. 1). The mechanics of fiber bridging in the crack wake are well understood (Li 1992; Kanda and $\mathrm{Li} \mathrm{1998);} \mathrm{however,} \mathrm{the} \mathrm{reinforcing} \mathrm{effect} \mathrm{of} \mathrm{fibers} \mathrm{in} \mathrm{the}$ frontal process zone (FPZ) of cementitious composites has not been researched as extensively. Yet, it is what happens in the FPZ that determines the first crack strength of the composite. Preventing the formation of the first crack is highly desirable in the design of durable thin sheet, fiber-reinforced cement composites. Its appearance signifies the onset of permanent damage. Cracking may initiate the processes that reduce durability. If the crack opens, the reinforcing fibers are exposed to environmental deterioration processes. However, if the crack does not, durability is not necessarily reduced. Crack width is strongly influenced by the stiffness, volume fraction, and bond properties of the fibers.

The failure processes in fiber-reinforced cement composites (FRCC) prior to formation of the first crack are very complex. To physically encapture the damage progression, an illustration is provided in Fig. 2. Initial flaws are always present in any cementitious material, whether it is a plain cement paste specimen or a fiber-reinforced cement composite. When load is first applied to

\footnotetext{
${ }^{1} \mathrm{PhD}$ Candidate, ACE-MRL, Dept. of Civil and Environmental Engineering, Univ. of Michigan, Ann Arbor, MI 48109. E-mail: pknelson@thetranstecgroup.com

${ }^{2}$ Professor and Director, ACE-MRL, Dept. of Civil and Environmental Engineering, Univ. of Michigan, Ann Arbor, MI 48109. E-mail: vcli@engin.umich.edu

${ }^{3}$ Associate Professor, Gifu Univ., Yanagido, Japan.

Note. Associate Editor: David A. Lange. Discussion open until March 1, 2003. Separate discussions must be submitted for individual papers. To extend the closing date by one month, a written request must be filed with the ASCE Managing Editor. The manuscript for this paper was submitted for review and possible publication on February 11, 2000; approved on October 18, 2001. This paper is part of the Journal of Materials in Civil Engineering, Vol. 14, No. 5, October 1, 2002. @ASCE, ISSN 0899-1561/ 2002/5-384-391/\$8.00+\$.50 per page.
}

the FRCC, areas of stress concentration develop at the tips of the initial flaws. With additional loading, microcracks form and grow in the frontal process zones ahead of the crack tips. It is assumed that the initial flaw will extend into the microcracked region when the microcracking has reached a saturated level. In pure cement matrix composites, microcracking is the most prevalent damage indicator prior to failure crack formation, as confirmed by the acoustic emission (AE) technique ( $\mathrm{Li}$ and Maalej 1996; Kamada et al. 1998).

Acoustic emissions (AEs) are the low level sonic or ultrasonic signals generated as a result of material deformation, degradation, or damage (Arrington 1987). When a microcrack forms in a composite, there is a release of stored elastic strain energy. This generates a stress wave that travels through the material and can be detected by AE sensors (Takumi et al. 1996). AE monitoring of fracture toughness specimens allows the stages of damage to be differentiated, including the microscopic events that accumulate prior to crack formation and the macroscopic events associated with crack extension (Kamada et al. 1998). For cement composites, $\mathrm{AE}$ activity is primarily associated with the cracking of the cement matrix. It can be assumed that microcracks have formed the instant the AE sensors detect the first stress wave.

Since the failure mechanisms prior to macrocrack formation are known, a composite can be specifically designed to have a high first crack strength. Betterman et al. (1995) investigated the effectiveness of microdiameter fibers as reinforcement in the frontal process zone (FPZ). Their composites were designed to have the microfibers arrest the development of microcracks. Betterman et al. compared the tensile behavior of three specimens: a pure cement paste specimen, a microdiameter FRCC, and a millimeter diameter FRCC. The first crack strength of the microdiameter FRCC was the highest. The microdiameter fibers were able to effectively arrest the growth of microcracks and to delay the onset of localized crack formation. A fiber is classified as a microfiber based on the size of the composite's initial flaw. In thin sheet FRCC, the initial flaw is approximately $60 \mu \mathrm{m}$ in length (Kim et al. 1999). Therefore, fibers with diameters less than or equal to $30 \mu \mathrm{m}$ will be deemed microdiameter fibers. 


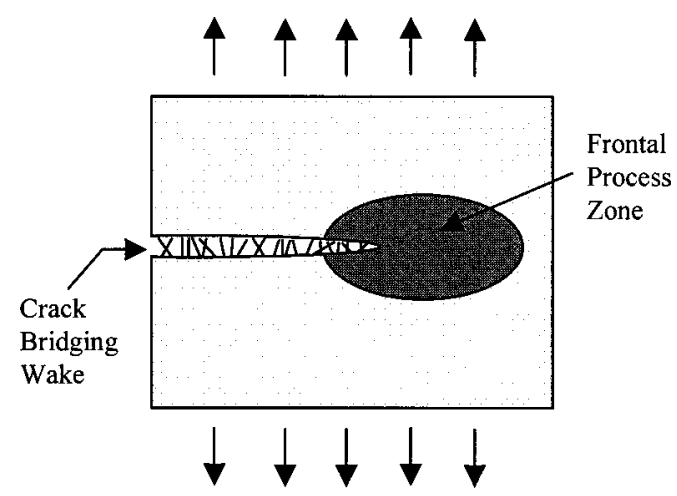

Fig. 1. Schematic of composite frontal process zone (FPZ) and crack bridging wake

\section{Objective}

The objective of this paper is to quantify the reinforcing ability of polypropylene (PP), polyvinylalcohol (PVA), and refined cellulose (RC) fibers in the frontal process zone (FPZ) of thin sheet, fiber-reinforced cement composites. Their reinforcement ability will be characterized by three fracture toughness parameters. They are:

- $K_{I C}^{M}$ : fracture toughness of the plain cement matrix,

- $K_{I C}^{C}$ : composite fracture toughness in the absence of microscopic damage, and

- $K_{I C}^{C^{*}}$ : composite fracture toughness that includes the energy absorbed in the microcracked region prior to failure crack localization.

$K_{I C}^{M}$ will be used as a reference. It will be compared to the composite fracture toughness values $K_{I C}^{C}$ and $K_{I C}^{C^{*}}$ to reveal how fibers influence the toughness (Fig. 3). The fracture toughness test results will be used in conjunction with the acoustic emissions technique to precisely identify the loading stress at which microcracks first form. An optical microscope will be used as well to visually observe the formation of the failure crack.

This paper is divided into four sections. First, the experimental test setups for the fracture toughness and acoustic emission testing are described. Second, the theoretical concepts used to analyze the test results are reviewed. Third, they are applied to the experimental fracture toughness test results. Finally, conclusions are drawn as to the efficiency of microfibers as reinforcement in the FPZ of thin sheet FRCC.

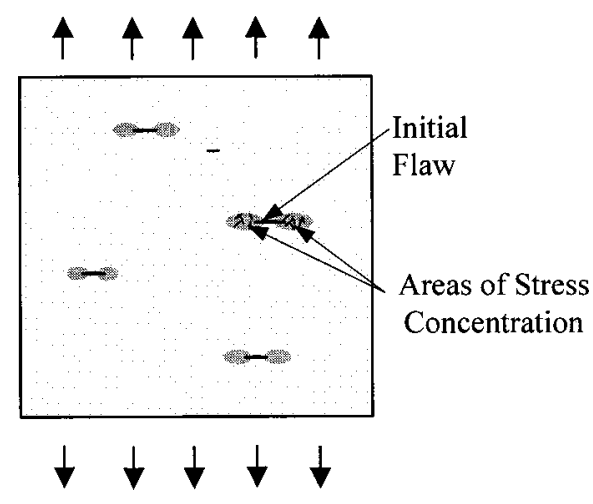

Fig. 2. Schematic of initial damage in FRCC
Table 1. Properties of Polypropylene (PP), Polyvinylalcohol (PVA), and Refined Cellulose (RC) Fibers Used in Laboratory and Hatschek Produced FRCC

\begin{tabular}{lccccc}
\hline Fiber & $\begin{array}{c}L_{f} \\
(\mathrm{~mm})\end{array}$ & $\begin{array}{c}d_{f} \\
(\mu \mathrm{m})\end{array}$ & $\begin{array}{c}\sigma_{f u} \\
(\mathrm{MPa})\end{array}$ & $\begin{array}{c}E_{f} \\
(\mathrm{GPa})\end{array}$ & $\begin{array}{c}V_{f} \\
(\%)\end{array}$ \\
\hline PP & 8 & 16.6 & 928 & 11.6 & 4.9 \\
PVA & 6 & 14.3 & 1,791 & 40 & 3.4 \\
RC & $0.1-3$ & $0.2-30$ & $500-900$ & $10-30$ & 5,10 \\
\hline
\end{tabular}

\section{Experimental Procedure}

\section{Materials}

Two series of FRCC were tested to determine composite fracture toughness. The first series was manufactured by the laboratory filter pressed slurry dewatered process. The composite matrix was composed of portland cement (Type I), silica fume, and limestone with a water-to-cement ratio of 0.25 . The mix proportions are silica fume-to-cement of $8.2 \%$ and limestone-to-cement of $12.9 \%$. Fiber orientation is two-dimensional as a result of processing. Polypropylene (PP), polyvinylalcohol (PVA), and refined cellulose (RC) fibers were used as reinforcement. Fiber dimensions, properties, and volume fractions are given in Table 1. All fibers have diameters less than $30 \mu \mathrm{m}$, so they can be classified as microdiameter fibers. The refined cellulose fibers are the kraft pulped Pinus radiata variety.

The second series of specimens was produced using the Hatschek process (Bentur and Mindess 1990) and they will be referred to as slates. These slates are reinforced by a combination of synthetic fibers (PP or PVA) and refined cellulose fibers. The hybrid fiber combinations are $\mathrm{PP}+\mathrm{RC}\left(V_{f} \mathrm{PP}=4.9 \%\right.$ and $V_{f} \mathrm{RC}$ $=5 \%)$ and $\mathrm{PVA}+\mathrm{RC}\left(V_{f} \mathrm{PVA}=3.4 \%\right.$ and $\left.V_{f} \mathrm{RC}=5 \%\right)$. The matrix composition and water-to-cement ratio of the slates are approximately the same as those given for the laboratory produced FRCC. However, the fibers are oriented preferentially in the longitudinal direction of the slate. These slates were pressed after manufacture.

\section{Fracture Toughness Specimens}

Fracture toughness specimens were cut from sheets of the FRCC using a diamond saw cutter. Typical specimen dimensions were $200 \times 25 \times 6 \mathrm{~mm}^{3}$ for the laboratory produced FRCC and $200 \times 25 \times 4 \mathrm{~mm}^{3}$ for the Hatschek produced ones (Fig. 4). The gauge length was $88 \mathrm{~mm}$ for all specimens, and $a / W$ (the ratio of initial notch length to specimen width) was between 0.20 and 0.27 . The initial notch was introduced using a Buehler diamond saw, and the notch tip was sharpened with a razor blade to simulate a sharp crack. Three laboratory specimens and two Hatschek specimens were tested for each fiber combination under air-dry conditions.

\section{Fracture Toughness Test Setup}

Fracture toughness testing was performed on a displacement controlled MTS 810 material testing system using a $3.3 \mathrm{kN}$ load cell. A universal joint was used to attach the load cell to the MTS machine to ensure pure tensile loading. A sliding grip held the top of the specimen, and a hydraulic grip held the bottom. Aluminum plates were epoxied to both ends of the fracture toughness specimens to facilitate gripping and to prevent the possibility of shear failure within the grip. The displacement rate of loading was $0.005 \mathrm{~mm} / \mathrm{s}$. 


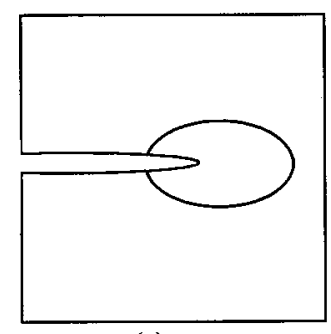

(a)

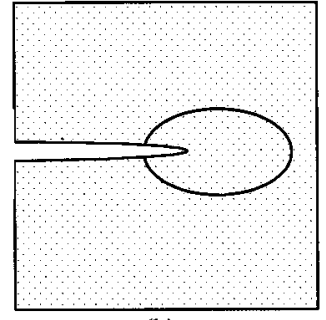

(b)

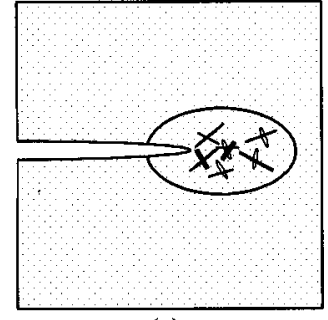

(c)

Fig. 3. Fracture toughness specimens: (a) Plain cement matrix $\left(K_{I C}^{M}\right)$; (b) Undamaged composite $\left(K_{I C}^{C}\right)$; and (c) Composite with saturated microcracking in FPZ $\left(K_{I C}^{C^{*}}\right)$

A double cantilever clip-on displacement gauge was used to measure the crack mouth opening displacement (CMOD) of the prenotch tip (Fig. 4). Resolution of the clip gauge was $1 \mu \mathrm{m}$, which is less than $3 \%$ of the displacement range encountered during testing. The clip gauge was attached to the specimen using a pair of metal knife edge pieces. They were placed equidistant from the prenotch tip on the specimen's side surface. The test results are presented here as nominal tensile stress versus crack mouth opening displacement $(\sigma$-CMOD) curves.

\section{Acoustic Emission (AE) Test Setup}

The acoustic emission (AE) system used was manufactured by Physical Acoustic Corporation. Two resonant $150 \mathrm{kHz}$ sensors detect the stress wave signals in the material as damage progresses. They were placed in the middle of the fracture toughness specimen, as shown in Fig. 5. The signals were amplified using a preamplifier of $40 \mathrm{~dB}$. The total gain was $80 \mathrm{~dB}$. The floating threshold level was set between 68 and $70 \mathrm{~dB}$. This level was adjusted prior to each test to enhance the stress wave signal and to reduce excess background noise. An acoustic grease couplant was used to attach the sensors to the specimen. It also aids in the detection of AE waves. Only average values of the typical $\mathrm{AE}$ waveform parameters, such as amplitude and duration, were

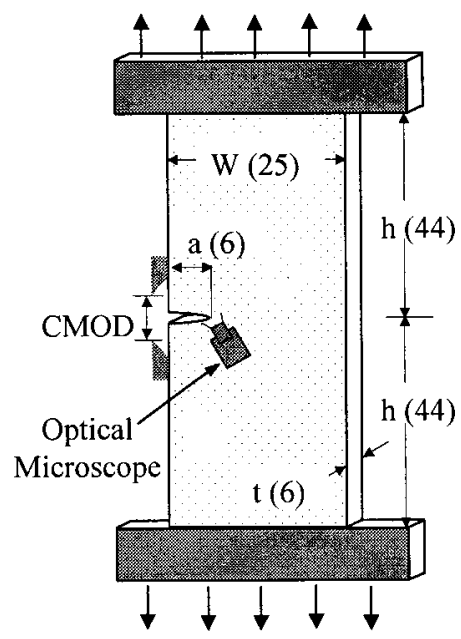

Fig. 4. Schematic of a typical fracture toughness specimen (all dimensions in $\mathrm{mm}$ ) stored in the data files. The AE equipment was only used on the Hatschek produced fracture toughness specimens.

\section{Optical Microscope}

An optical microscope was used to visually monitor crack formation during fracture toughness testing (Fig. 4). The 50× magnification optical microwatcher lens was focused on the notch tip. This allows the visual frontal crack processes to be correlated directly to the nominal tensile stress versus crack mouth opening displacement $(\sigma-\mathrm{CMOD})$ curves.

\section{Theoretical Concepts}

Linear elastic fracture mechanics (LEFM) can be applied to the analysis of cementitious materials if the frontal process zone (FPZ) ahead of the initial notch tip is small when compared to the other planar specimen dimensions (Cotterell and Mai 1996). Because this requirement can only be confirmed after testing, an estimate of the material's fracture toughness must be made when sizing the specimens. If the so called "small scale yielding" condition is satisfied, the measured fracture toughness is the true material fracture toughness $K_{I C}^{C}$.

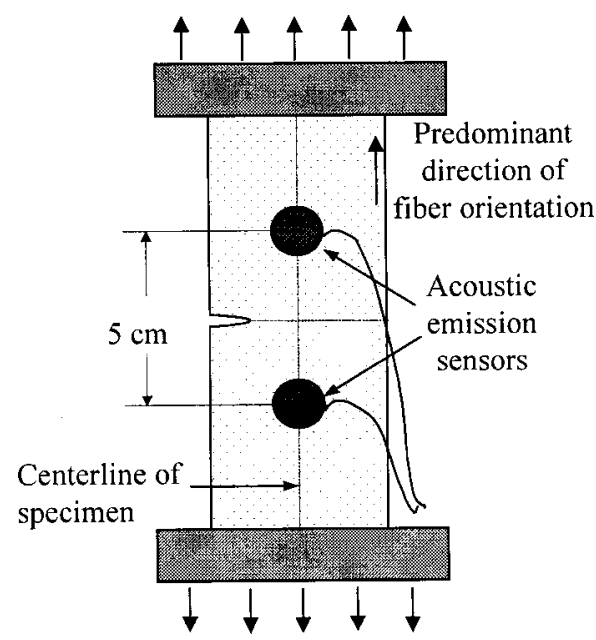

Fig. 5. Location of acoustic emission sensors on a fracture toughness specimen 


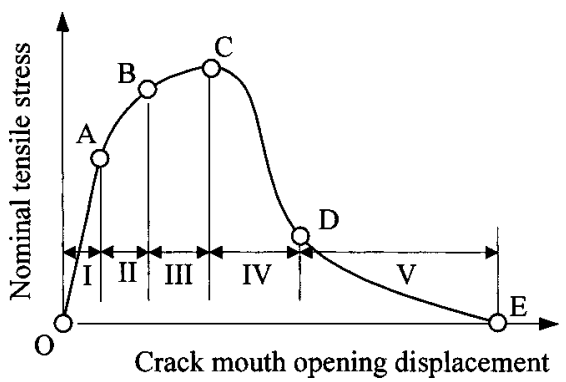

Fig. 6. Typical nominal tensile stress versus crack mouth opening displacement $(\sigma-\mathrm{CMOD})$ curve

\section{Data Analysis}

The fracture processes in FRCC will be better understood by examining the following five elements:

1. The nominal tensile stress versus crack mouth opening displacement ( $\sigma$-CMOD) curve (Fig. 6);

2. The stages of composite damage (Fig. 7);

3. Composite fracture toughness $K_{I C}^{C}$ and $K_{I C}^{C^{*}}$;

4. The optical micrographs of damage progression (Figs. 8-12); and

5. The acoustic emissions data.

\section{Nominal Tensile Stress versus Crack Mouth Opening Displacement (o-CMOD) Curves}

A typical nominal tensile stress versus crack mouth opening displacement $(\sigma$-CMOD) curve can be divided into five zones (Fig. $6)$. Zone I is characterized by linear-elastic behavior. Zone II contains the nonlinear deformation of the composite resulting from microcrack formation. In Zone III, the localized failure crack has formed and is growing in a stable manner. Zone IV contains the unstable growth of the localized failure crack. Finally, in Zone V, the failure crack has propagated across the entire specimen's width, and only the bridging fibers carry load. The five zones are bounded by the following five stresses: $\sigma_{A}, \sigma_{B}, \sigma_{C}, \sigma_{D}$, and $\sigma_{E}$ (Fig. 6). $\sigma_{A}$ signifies the deviation from linear-elastic behavior. $\sigma_{B}$ indicates the formation of a visible crack at the notch tip. $\sigma_{C}$ corresponds to the peak nominal tensile stress. $\sigma_{D}$ is the stress when only bridging fibers are sustaining load, and $\sigma_{E}$ is the zero stress at the end of the test. The failure mechanisms associated with these five stages are illustrated in Fig. 7. Each stage is discussed in greater detail in the following sections.

\section{Zone I: Linear-Elastic Behavior of FRCC}

In Zone I, the composite is deforming linear-elastically under load (Fig. 8). The resultant stress profile near the notch tip is shown in Fig. 7(a). No microcracks have yet formed. The mode I loading stress intensity factor $\left(K_{L}\right)$ is less than the composite material's resistance $\left(K_{I C}^{C}\right)$, and the loading stress $(\sigma)$ is less than $\sigma_{A}$ :

$$
\text { Zone I: } K_{L}<K_{I C}^{C} \text { and } \sigma<\sigma_{A}
$$

The linear-elastic behavior terminates when $\sigma_{A}$ is reached. $\sigma_{A}$ is used to calculate the composite fracture toughness $\left(K_{I C}^{C}\right)$ :

$$
K_{I C}^{C}=F(a / W) \sigma_{A} \sqrt{ } \pi a
$$

where $F(a / W)=$ specimen shape factor (Tada et al. 1985); $a=$ initial notch length; and $W=$ specimen width. $K_{I C}^{C}$ is always greater than or equal to the fracture toughness of a monolithic cement paste specimen $\left(K_{I C}^{M}\right)$.

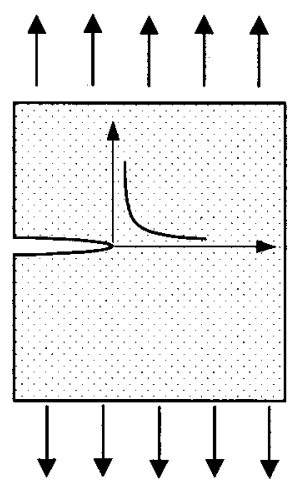

(a)

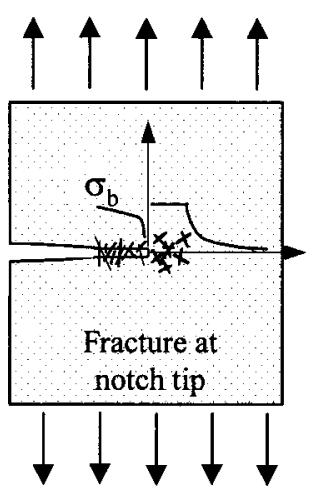

(c)

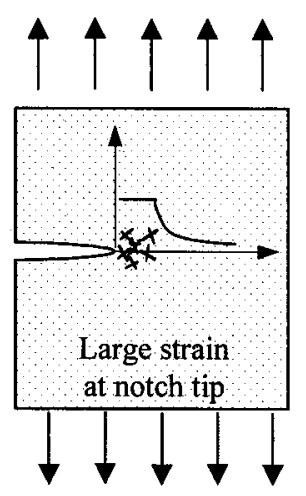

(b)

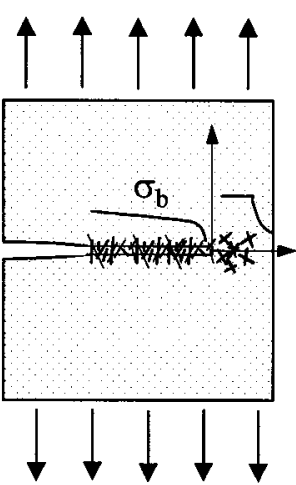

(d)

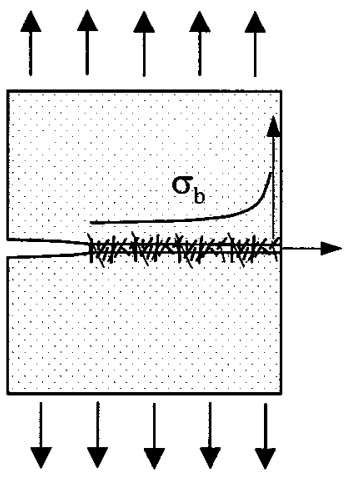

(e)

Fig. 7. Stages of composite damage: (a) Zone I: Linear-elastic behavior; (b) Zone II: Microcrack formation in the frontal process zone (FPZ); (c) Zone III: Stable growth of failure crack; (d) Zone IV: Unstable growth of failure crack; and (e) Zone V: Fiber bridging of failure crack

\section{Zone II: Nonlinear Deformation of FRCC}

The FRCC is more compliant in Zone II (Fig. 6). This loss of stiffness is associated with the formation and opening of microcracks in the FPZ ahead of the notch tip [Fig. 7(b)]. Microcracks may or may not be visible on the surface of the composite, and none can be seen in Fig. 9. During Zone II, the loading stress intensity factor $\left(K_{L}\right)$ is greater than $K_{I C}^{C}$ and less than $K_{I C}^{C^{*}} \cdot K_{I C}^{C^{*}}$ is defined as composite fracture toughness, which includes the energy absorbed in the microcracked FPZ prior to crack localization:

$$
\text { Zone II: } K_{I C}^{C}<K_{L}<K_{I C}^{C^{*}} \text { and } \sigma_{A}<\sigma<\sigma_{B}
$$




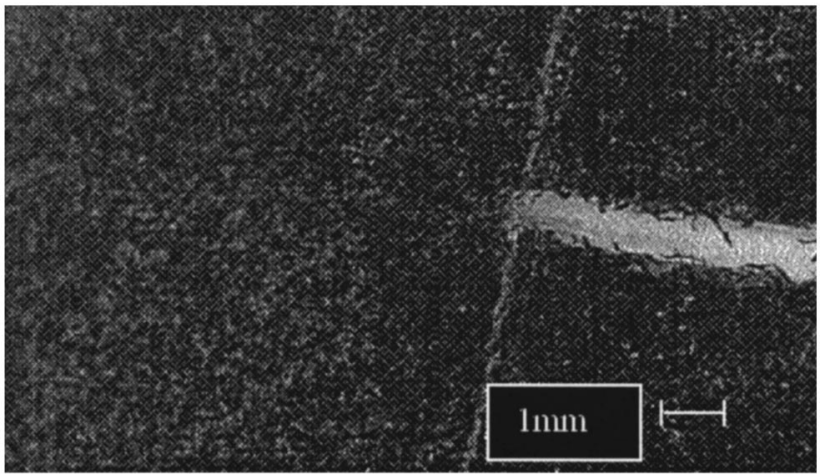

Fig. 8. Zone I: Linear elastic behavior (50×) (line used for notch sizing purposes)

$K_{I C}^{C^{*}}$ is quantified using $\sigma_{B}$, the loading stress when the localized failure crack appears. The optical microscope pictures were used to identify this stress point. Zone II ends with the appearance of the localized failure crack. If the microdiameter fibers do not bridge the forming microcracks in the frontal process zone, then $\sigma_{A}$ will be close to $\sigma_{B}$ and $K_{I C}^{C}$ will approximate $K_{I C}^{C^{*}}$.

\section{Zone III: Stable Growth of Localized Failure Crack through FRCC}

A distinct localized failure crack can now be seen (Fig. 10). The microcracked zone is assumed to propagate ahead of the lengthening failure crack [Fig. 7(c)], with the fibers bridging in the crack wake. Since additional load needs to be placed on the specimen in order for the crack tip to propagate, it is apparent that the loading stress intensity factor $\left(K_{L}\right)$ is less than or equal to the material resistance to crack formation $\left(K_{I C}^{C^{*}}-K_{b}\right)$. For Zone III behavior

$$
K_{L} \leqslant K_{I C}^{C^{*}}-K_{b} \text { and } \sigma_{B}<\sigma<\sigma_{C}
$$

where $K_{b}=$ negative stress intensity factor due to fiber bridging (Kim 1999). The fiber bridging resistance increases monotonically as the fibers debond and the crack opens. Propagation of the failure crack is stable:

$$
\frac{\partial K_{L}}{\partial a}<\frac{\partial}{\partial a}\left(K_{I C}^{C^{*}}-K_{b}\right)
$$

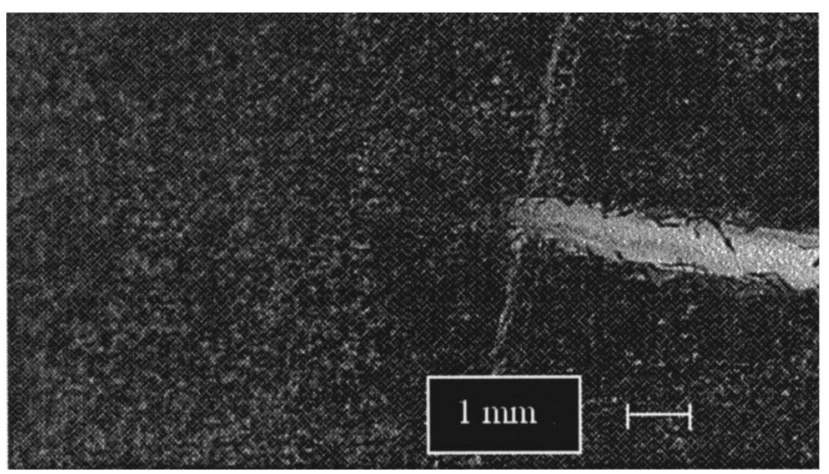

Fig. 9. Zone II: Nonlinear deformation $(50 \times)$ (line used for notch sizing purposes)

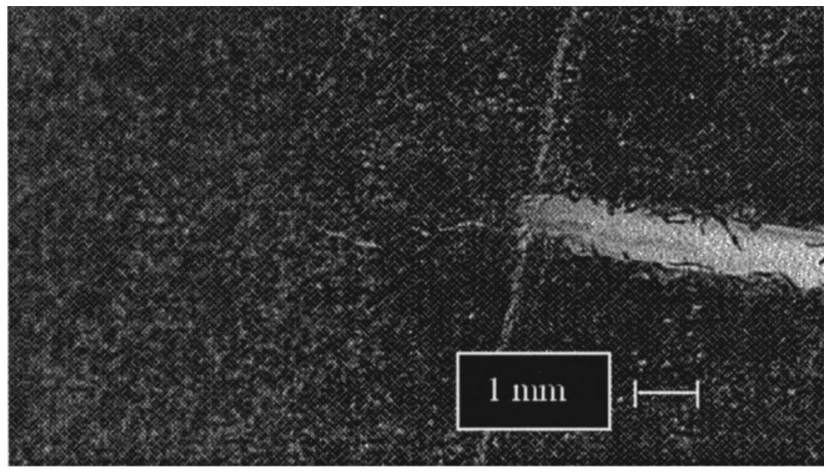

Fig. 10. Zone III: Stable growth of localized failure crack $(50 \times)$ (line used for notch sizing purposes)

The above equation states that the rate of change in load stress intensity factor $\left(K_{L}\right)$ with increasing crack length is less than the rate of change in material resistance $\left(K_{I C}^{C^{*}}-K_{b}\right)$ with increasing crack length. Zone III ends when the peak stress $\left(\sigma_{C}\right)$ is reached.

\section{Zone IV: Unstable Growth of Localized Failure Crack}

In Zone IV, the crack tip propagates through the entire specimen width in an unstable manner [Figs. 7(d) and 11]. The loading stress intensity factor equals the material resistance to crack propagation:

$$
K_{L}=K_{I C}^{C^{*}}-K_{b}
$$

This can also be restated in terms of crack length. The rate of change in $K_{L}$ with increased crack length is greater than the rate of change in material resistance $\left(K_{I C}^{C^{*}}-K_{b}\right)$ with increased crack length:

$$
\frac{\partial K_{L}}{\partial a}>\frac{\partial}{\partial a}\left(K_{I C}^{C^{*}}-K_{b}\right)
$$

Zone IV is delineated by loading stresses $\sigma_{C}$ and $\sigma_{D}$.

\section{Zone V: Fiber Bridging of Localized Failure Crack}

At the start of Zone V, all the tensile load is carried by the fibers bridging the failure crack. The fibers are either pulling out or rupturing [Figs. 7(e) and 12]. The specimen can no longer sustain load when $\sigma=\sigma_{E}$.

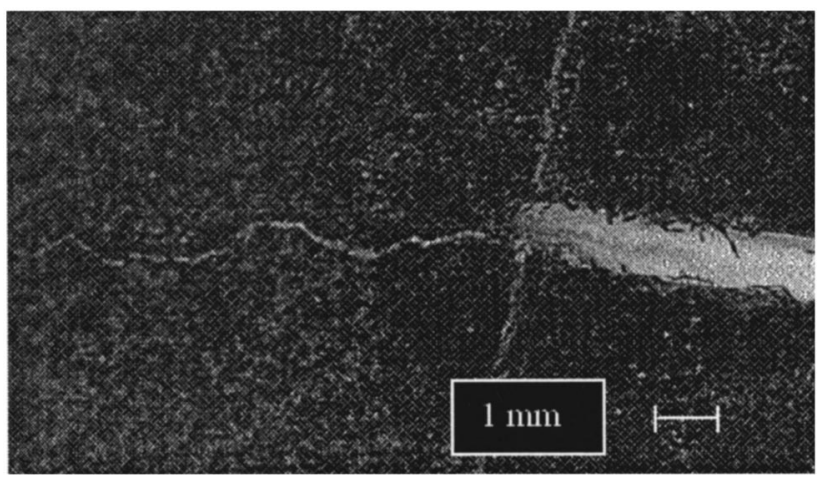

Fig. 11. Zone IV: Unstable growth of localized failure crack $(50 \times)$ (line used for notch sizing purposes) 


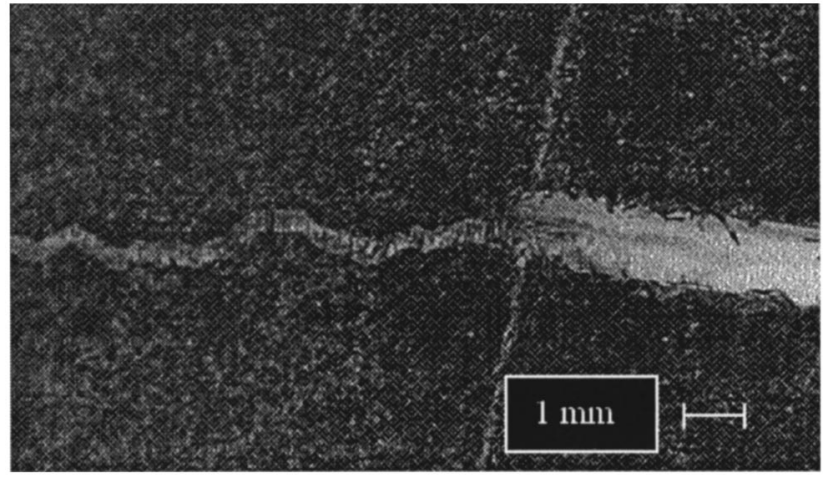

Fig. 12. Zone V: Fiber bridging of localized failure crack $(50 \times)$ (line used for notch sizing purposes)

\section{Results}

\section{Laboratory Produced Fracture Toughness Specimens}

To assess the toughening effectiveness of the microfibers in the FPZ, the measured $K_{I C}^{C}$ values for the laboratory produced fracture toughness specimens are compared with the fracture toughness of hardened cement paste, $(\mathrm{HCP}), K_{I C}^{M} . K_{I C}^{M}$ ranges from 0.2 to $0.3 \mathrm{MPa} \sqrt{\mathrm{m}}$ for cement specimens that contain silica fume and have a water-to-cement ratio of 0.3 (Igarashi and Kawamura 1995; Li et al. 1995). Representative nominal tensile stress versus crack mouth opening displacement $(\sigma$-CMOD) curves for the laboratory specimens are shown in Figs. 13 and 14. For the polypropylene (PP) fiber-reinforced fracture toughness specimens, a load instability is apparent in the $\sigma$-CMOD curve after linearelastic deformation (Fig. 13). $\sigma_{A}$ is very close to $\sigma_{B}$, meaning the fibers were not able to stabilize microcrack formation prior to the development of the localized failure crack. The measured $K_{I C}^{C}$ value falls within the range of hardened cement paste fracture toughness values (Fig. 15). This implies that the PP fibers are not effective in delaying the formation of a localized failure crack. For the PVA fracture toughness specimens, no load instability is apparent in the $\sigma$-CMOD curve (Fig. 13). Its measured composite fracture toughness is greater than that of the HCP (Fig. 15). This means that the PVA fibers effectively postpone the onset of microscopic composite damage. Microcracking does toughen the PVA com-

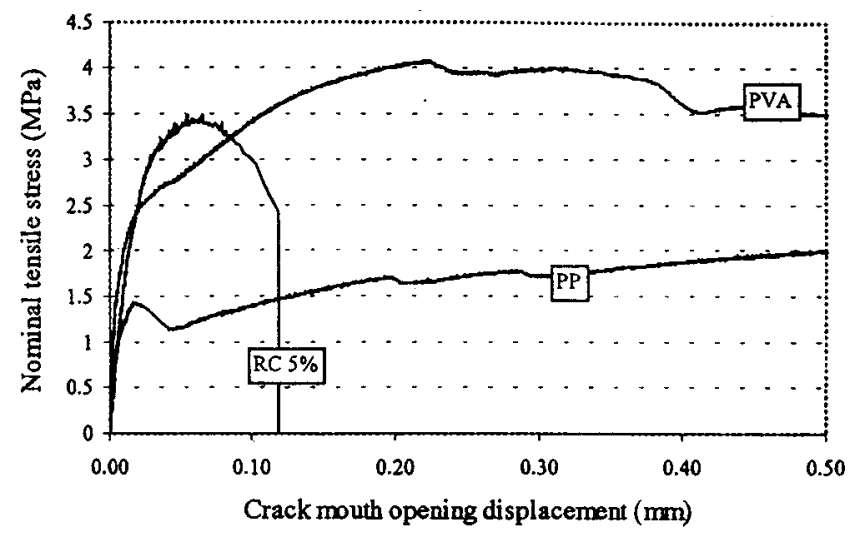

Fig. 13. Typical nominal tensile stress versus crack mouth opening displacement curves for PP, PVA, and RC laboratory produced fracture toughness specimens

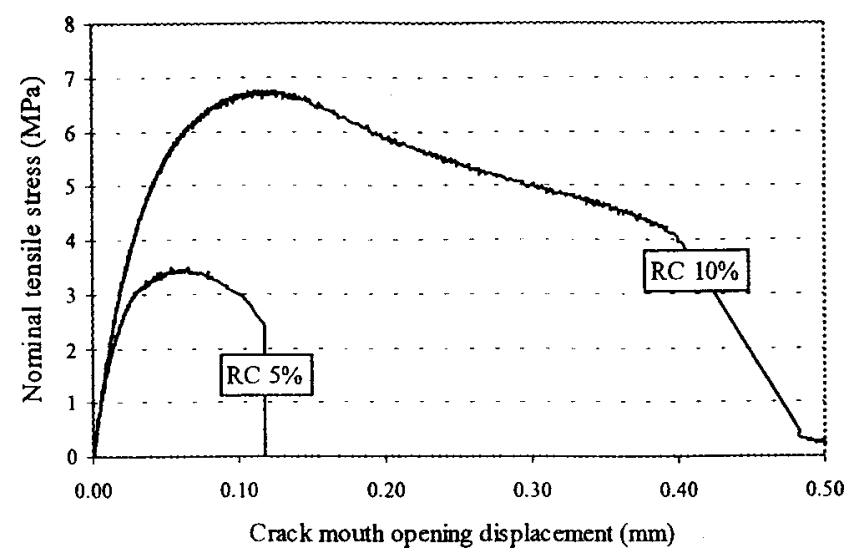

Fig. 14. Typical nominal tensile stress versus crack mouth opening displacement curves for 5 and $10 \%$ RC laboratory produced fracture toughness specimens

posites as well, with $\left(K_{I C}^{C^{*}} / K_{I C}^{C}\right) \geqslant 1.4$. The PVA fibers are bridging the forming microcracks and are delaying the formation of the localized failure crack.

The difference in behavior between the PP and PVA fibers in the frontal process zone must be attributed to their interaction with the cement matrix. The PVA fiber has a strong chemical and frictional interfacial bond to the cement matrix, while the PP fiber has only a weak frictional bond (Kanda and Li 1998; Kim 1999). As listed in Table 1, the length and diameter of the PP and PVA fibers are comparable, but the strength and stiffness of the PVA fiber is superior to that of the PP one. Strong interfacial bond and high fiber stiffness can be expected to produce strong bridges that resist the opening of the microcracks in the FPZ.

Typical $\sigma$-CMOD curves for the refined cellulose fracture toughness specimens ( $V_{f}$ of 5 and $10 \%$ ) are shown in Fig. 14. The $\mathrm{RC}$ fibers are able to delay the formation of microcracks in the composites $\left(K_{I C}^{C}>K_{I C}^{M}\right)$. Doubling the RC fiber volume fraction translates to a doubling of its $K_{I C}^{C}$ (Fig. 15). Likewise, the RC fibers bridge the microcracks with $\left(K_{I C}^{C^{*}} / K_{I C}^{C}\right)>1.2$. The RC fibers effectively delay localized failure crack formation for both fiber volume fractions. The effectiveness of the RC fibers in the frontal process zone is comparable to that of the PVA fibers.

\section{Hatschek Produced Fracture Toughness Specimens}

Fracture toughness of the Hatschek produced specimens was measured using mechanical testing and the acoustic emission

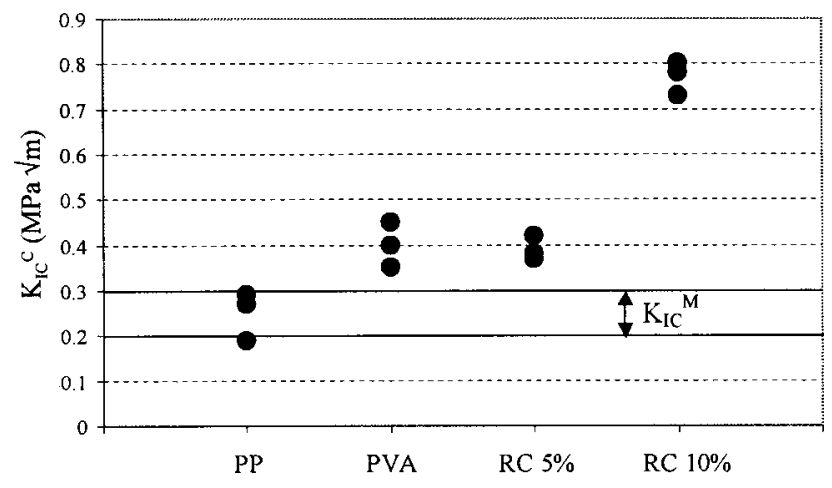

Fig. 15. PP, PVA, and RC $\left(V_{f}=5\right.$ and $\left.10 \%\right) K_{I C}^{C}$ fracture toughness values 


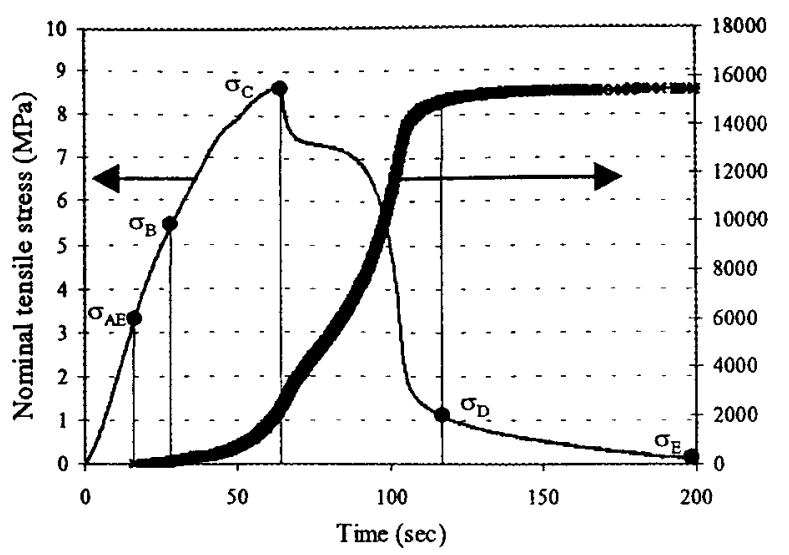

Fig. 16. Typical nominal tensile stress versus time and cumulative AE hits versus time curves for Hatschek produced slate

(AE) technique. The $\mathrm{AE}$ test results can be used to confirm the accuracy of the mechanically obtained composite fracture toughness values. A typical nominal tensile stress versus time and cumulative AE hits versus time plot for a Hatschek slate is shown in Fig. 16. Testing time was used to correlate AE hits to nominal tensile stress. One AE hit is recorded each time the AE sensors detect a stress wave. The five stages of composite damage can be identified from the changes in slope of the cumulative AE hits versus time curve. For Zone I: linear elastic behavior, no AE hits are recorded because the composite sustains no microscopic damage. The first AE hit is recorded when Zone II (nonlinear composite deformation) begins. This corresponds to stress $\sigma_{A E}$, which is used to calculate composite fracture toughness, $A E-K_{I C}^{C}$. It is denoted like this to distinguish it from $K_{I C}^{C}$, calculated using $\sigma_{A}$. As damage progresses, the slope of the AE curve increases slightly. After the peak stress is reached, there is a marked increase in slope. Unstable cracking of the cement matrix is releasing a great amount of elastic strain energy. In Zone V, when the fibers are either pulling out or rupturing in the crack bridging wake, the cumulative AE hits versus time curve plateaus.

When comparing the mechanical fracture toughness values to the AE fracture toughness values, it is found that $K_{I C}^{C}$ is always greater than or equal to $A E-K_{I C}^{C}$. The difference between the two values is not more than $30 \%$. This reveals that the material's fracture toughness is likely overestimated when the mechanical $\sigma$-CMOD curves are used to quantify $K_{I C}^{C}$. This trend can be explained. When the AE sensors detect the first hit, microscopic damage has initiated. However, the material's global deformation remains linear elastic. An increase in specimen compliance is not yet noticeable. $K_{I C}^{C}$ determination using the stress at incipient nonlinearity in the $\sigma$-CMOD curve may be regarded as an upper bound of the true fracture toughness value.

The $\sigma$-CMOD curves for the Hatschek produced fracture toughness specimens reinforced with $\mathrm{PP}+\mathrm{RC}$ and $\mathrm{PVA}+\mathrm{RC}$ fibers are shown in Fig. 17. For these slates, composite fracture toughness $K_{I C}^{C}$ is much greater than $K_{I C}^{M}$. The microdiameter fibers effectively delay microcrack formation in the frontal process zone. Also, the fracture behavior of these Hatschek slates is independent of the reinforcing synthetic fiber type. $K_{I C}^{C}$ of $\mathrm{PP}+\mathrm{RC}$ slate is $1.27 \mathrm{MPa} \sqrt{\mathrm{m}}$, and $K_{I C}^{C}$ of PVA+RC slate is $1.28 \mathrm{MPa} \sqrt{\mathrm{m}}$. However, microcrack toughening of the slates is negligible with $\left(K_{I C}^{C^{*}} / K_{I C}^{C}\right)<1.2$. The Hatshek slates resist microscopic damage effectively, but are not toughened by microcracks.

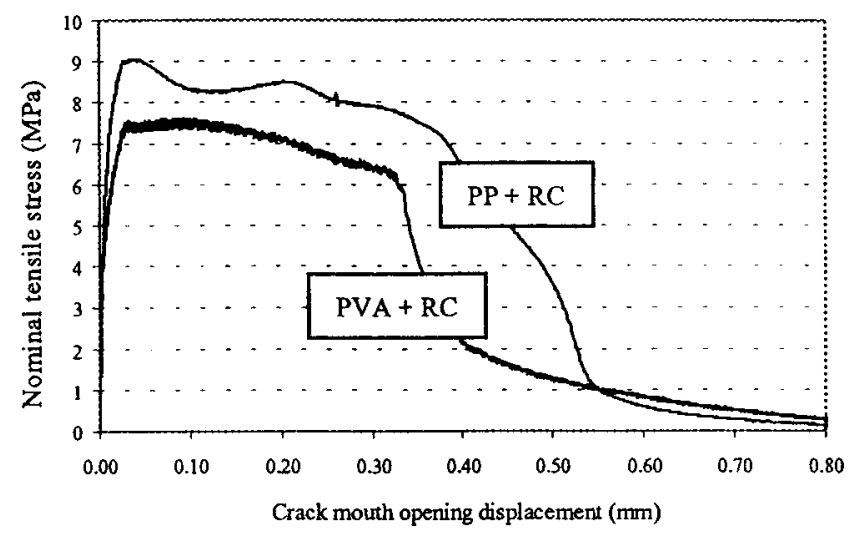

Fig. 17. Typical nominal tensile stress versus crack mouth opening displacement curves for $\mathrm{PP}+\mathrm{RC}$ and $\mathrm{PVA}+\mathrm{RC}$ Hatschek produced fracture toughness specimens

\section{Conclusions}

The primary objective of this paper was to assess the reinforcing ability of microdiameter fibers in the frontal process zone ahead of an initial flaw. To do this, both mechanical fracture toughness testing and the acoustic emissions technique were used. Five stages of composite damage were determined. They are: Zone I, linear-elastic behavior; Zone II, nonlinear deformation; Zone III, stable growth of the failure crack; Zone IV, unstable growth of the failure crack; and Zone V, fiber bridging of the crack.

Laboratory produced composites reinforced with PP, PVA, and $\mathrm{RC}$ fibers were tested to obtain fracture toughness. The PP fibers did not provide reinforcement ahead of the crack; their composite fracture toughness was approximately equal to that of the matrix $\left(K_{I C}^{C} \mathrm{PP} \approx K_{I C}^{M}\right)$. The PVA and RC fibers did effectively postponing the development of the microcracks. Their composite fracture toughness was greater than that of the matrix by $40 \%$. The reason for the different microcrack bridging efficiency of the PP versus the PVA and RC fibers can be related to their different fiber properties and modes of interfacial bonding.

For the Hatschek produced slates, the hybrid fiber reinforcement provided great toughening. Composite fracture toughness $K_{I C}^{C}$ was five times greater than $K_{I C}^{M}$ for both the $\mathrm{PP}+\mathrm{RC}$ and the $\mathrm{PVA}+\mathrm{RC}$ fiber-reinforced slates. However, microcrack toughening of the slates was negligible.

The acoustic emission (AE) data obtained confirmed the accuracy of the measured fracture toughness values. The fracture toughness values obtained via mechanical testing are likely to overestimate fracture toughness. The acoustic emission test can identify damage at its initiation, while a change in global specimen stiffness is required before it is apparent in the $\sigma$-CMOD curve. The mechanical fracture toughness value is regarded as an upper bound of the true fracture toughness value.

\section{Acknowledgments}

The writers acknowledge support of this work by REDCO of Belgium and Eternit of Switzerland. Funding for the first writer's graduate studies at the University of Michigan was provided by the National Science Foundation. 


\section{References}

Arrington, M. (1987). "Chapter 2: Acoustic emission.” Non-destructive testing of fibre-reinforced plastics composites, Vol. 1, J. Summerscales, ed., Elsevier, Essex, U.K., 25-63.

Bentur, A., and Mindess, S. (1990). Fibre reinforced cementitious composites, Elsevier, Essex, U.K.

Betterman, L. R., Ouyang, C., and Shah, S. P. (1995). "Fiber-matrix interaction in microfiber-reinforced mortar." Adv. Cem. Based Mater. 2(2), 53-61.

Cotterell, B., and Mai, Y. W. (1996). Fracture mechanics of cementitious materials, Balckie, Glasgow, U.K.

Igarashi, S.-I., and Kawamura, M. (1995). "Detection of failure around main cracks and their relation to the fracture toughness of cement pastes." J. Am. Ceram. Soc., 7(78), 1715-1718.

Kamada, T., Iwanami, M., and Nagataki, S. (1998). "Acoustic emission discrimination of crack types in reinforced concrete beams." Fracture Mechanics of Concrete Structures: Proc., FRAMCOS-3, AEDIFICATIO Publishers, Frieburg, Germany, 57-66.

Kanda, T., and Li, V. C. (1998). "Interface property and apparent strength of high strength hydrophilic fiber in cement matrix." J. Mater. Civ. Eng., 10(1), 5-13.

Kim, P. J. (1999). "Micromechanics based durability study of lightweight thin sheet fiber reinforced cement composites." $\mathrm{PhD}$ thesis, Univ. of Michigan at Ann Arbor, Ann Arbor, Mich.

Kim, P. J., Wu, H. C., Lin, Z., Li, V. C., deLhoneux, B., and Akers, S. A. S. (1999). "Micromechanics-based durability study of cellulose cement in flexure." Cem. Concr. Res., 29, 201-208.

Li, V. C. (1992). "Postcrack scaling relations for fiber-reinforced cementitious composites." J. Mater. Civ. Eng., 4(1), 41-57.

Li, V. C., and Maalej, M. (1996). "Toughening in cement based composites. Part I: Cement, mortar, and concrete." Cem. Concr. Compos., 18, 223-237.

Li, V. C., Mishra, D. K., and Wu, H. C. (1995). "Matrix design of pseudo strain-hardening fiber reinforced cementitious composites." RILEM J. Mater. Struct., 28(183), 586-595.

Tada, H., Paris, P. C., and Irwin, G. R. (1985). The stress analysis of cracks handbook, 2nd Ed., Paris Proceedings, St. Louis.

Takumi, S., Kouhei, N., and Yuzuru, S. (1996). "Surface-crack growth mechanisms of composite materials." Proc., Progress in Acoustic Emission VIII, Japanese Society for NDI, Japan, 41-46. 